\title{
ENTRE-VISTAS COM O PROFESSOR ALESSANDRO PORTELLI ${ }^{1}$ INTER-VIEWS WITH THE PROFESOR ALESSANDRO PORTELLI
}

\author{
Prof. Dr. Erinaldo Cavalcanti ${ }^{2}$ \\ Prof. Dr. Pere Petit ${ }^{3}$ \\ Prof. Dr. Dernival Venâncio Ramos Júnior ${ }^{4}$
}

\section{Introdução}

O historiador italiano Alessandro Portelli esteve em Manaus, AM, em outubro de 2017. Ele veio participar como conferecista do X Encontro da Regional Norte de História: (des)colonialidades, memóris e linguagens na Amazônia. $\mathrm{Na}$ oportunidade, ele nos concebeu uma entrevista que transcrevemos abaixo.

Alessandro Portelli nasceu em Roma no ano de 1942. Historiador e musicólogo, ele se tornou uma das principais teóricos e praticantes da História oral no mundo. A sua vasta bibliogria inclui dezenas de livros e ensaios, traduzidos para diversos idiomas entre eles o inglês, o espanhol e o português.

No Brasil, são vários os artigos publicados nas principais revistas da área de História e em coletâneas como o clássico Usos e abusos da História oral, organizada por Janaína Amado e Marieta de Moraes Ferreira em 1996. A editora Letra e Voz de São Paulo

\footnotetext{
${ }^{1}$ Transcrição de Mery Andrades e tradução de Dernival Venâncio Ramos Júnior.

2 Doutor em História pela Universidade Federal de Pernambuco. Professor do curso de História da Universidade Federal do Sul e Sudeste do Pará, UNIFESSPA, onde coordena o Grupo de Pesquisa Itempo: Interpretações do Tempo: Ensino, memória, narrativa e política.

${ }^{3}$ Doutor em História pela Universidade de São Paulo. Professor do Programa de Pós-graduação em História da UFPA e coordenador da Associação Nacional de História Oral, biênio 2018-2020. Também é coordenador do Grupo de Pesquisa História do Tempo Presente na Amazônia.

${ }^{4}$ Doutor em História pela Universidade de Brasília. Professor do Curso de História, do Mestrado Profissional em Ensino de História e do Programa de Pós-graduação em Estudos de Cultura e Território da UFT/Araguaína. Coordena o Grupo de Pesquisa História, Cultura e Território.
} 
publicou os seus principais ensaios através dos títulos Ensaios de História oral de 2010 e História oral como arte da escuta de 2016

Entrevistadores: Antes de entrarmos nos temas que pretendemos aprofundar nesta entrevista, lhe agradeceríamos se nos falasse um pouco sobre a sua história de vida.

Alessandro Portelli: Eu nasci em Roma, porém cresci em Terni que é uma cidade industrial, a cidade do aço. Meu pai trabalhava na prefeitura de Terni. O importante é que no bairro onde vivíamos, a minha era a única família de trabalhadores que não estavam vinculados à fábrica, uma fábrica química. Foi junto com operário e técnicos que eu cresci. Sempre nos identificávamos como passantes, nunca nos identificávamos como de Terni. Eu não absorvi a maneira de falar da cidade. Minha irmã, que é nove anos mais nova que eu, falava italiano e eu falo o dialeto romano porque me defendia desta identificação. Retornei a Roma com 18 anos.

E: O senhor estudou na Universidade de Roma?

A. P: Em Roma, estudei direito e me licenciei em direito, porém não era uma coisa que me interessava. Só que eu não sabia muito bem o que fazer... Encontrei um trabalho em um centro de investigações, trabalhei como administrador na seção internacional. Era um trabalho seguro, tranquilo e sobrava bastante tempo para fazer outras coisas, porém logo ocorreram os movimentos estudantis dos anos de 1960. Eu era um pouco mais velho que a maioria das pessoas do movimento. Quando o movimento estalou em 67, tinha 25 anos e já trabalhava.

E: Como os estudos sobre a música popular influenciaram as suas pesquisas?

A. P: Eu havia morado um ano nos Estados Unidos da América e descobri a música popular americana, a luta pelos direitos civis, o movimento pacifista... Ao voltar para a Itália perguntei-me se não havia algo desse tipo na Itália. Comecei a viajar ao centro da Itália 
com um objetivo político, recolhendo músicas populares, músicas tradicionais... A coisa que é específica da Itália, e talvez da Espanha, é que os movimentos revolucionários, o comunismo, o socialismo, eram também parte da cultura popular. Foram movimentos intelectuais, teóricos, e na Itália, como na Espanha e em Portugal, existem muita música tradicional, folclórica, com conteúdo político. O centro político da cultura operária mais próximo de Roma é Terni e eu comecei fazendo entrevistas com os movimentos populares. Uma coisa da qual me dei conta é que os operários, os que haviam estado na resistência, os partisanos, nunca contavam algo sem me contar uma história, só que me dei conta de que a história que me contavam era totalmente equivocada. Se confundiam com as datas, se equivocavam com os contextos. Eu me perguntei 'por quê?', 'o que estaba acontecendo?' Porque não era apenas um indivíduo com um memoria falha, era um fato cultural. Aos 35 anos, eu nunca havia ouvido falar de fontes orais nem de história oral. Isso foi algo que eu descobri naquele momento e de maneira empírica.

E: Professor, como ocorreu seu encontro com a História como campo de conhecimento? Foi antes mesmo da História oral? O que o senhor lembra dessa experiência?

A. P: Em finais dos anos de 1960, o que eu fiz foi voltar à Universidade. O trabalho me deixava muito tempo para assistir aulas e eu me graduei em literatura norte-americana porque era isso o que me interessava desde que fui aos Estados Unidos. Lia muitos livros de história, sempre li muito, porém nunca fiz um curso de História na universidade, era mais vinculado com a militância política. No contexto da música popular, eu havia entrado em contato com o movimento que se chama em italiano Mocco Canción e com o Instituto Ernesto de Martino, fundado por Gianni Bosio, que era historiador, porém um historiador que era difícil imaginar no partido comunista ou socialista.... Ele era um socialista do tempo purgiano-libertário. Gianni Bosio dizia que não era possível que a história da classe operária se identificasse com a história dos partidos operários e que a história dos partidos operários se identificava com a história dos grupos dirigentes dos partidos operários. Ele dizia que era preciso estudar a história da classe operária, das classes não hegemônicas, com suas próprias fontes, as fontes que eles mesmos criam e que o estudo da música popular era um estudo de história e não uma pesquisa de folclore. A canção popular é uma 
das formas pelas quais as classes não hegemônicas contam sua própria história e afirmam sua presença no mundo. Entre 1967 e 1974 ou 1975, o que mais me interessava era a música. Contudo, eu não sou um músico, sou completamente desafinado e não podia fazer nada com a música. O único que podia fazer era estudá-la, guardá-la nos arquivos, passá-la a músicos militantes, ativistas, para que eles a utilizassem em suas atividades. Como estava me formando em literatura, naquele momento, comecei a estudar teoria literária pósmoderna, que era uma coisa que me interessava muito...

E: Nas suas pesquisas, além de fontes orais, o senhor utilizou outros documentos?

A. P: Em finais dos anos de 1970, eu tinha o projeto de escrever um libro sobre a polaridade norte-americana, um libro de História oral sobre a classe operária americana e um libro de Historia oral sobre a classe operária italiana. Escrevi o libro que se intitula The Text and The Voice ${ }^{5}$ que é uma análise sobre o uso da palavra oral, da oralidade na literatura norte-americana, um libro sobre os mineiros nos Estados Unidos. Em 2004, houve uma greve em Terni e então escrevi um segundo livro sobre a greve e agora os juntamos, saíram juntos em italiano e em inglês ${ }^{6}$. A minha ideia era que a história do mundo popular era uma história que tínhamos que estudar com suas próprias fontes. Não quer isso dizer que não podíamos usar arquivos, periódicos e a historiografia, porém existiam historiadores na Itália que diziam que não se podia usar fontes orais se existem outras fontes. A primeira fonte de informação que eu tenho sobre uma história, um acontecimento, é a fonte oral e depois vou usar as fontes de arquivo. Eu as utilizo todas, porém a forma, a organização do relato que vou escrever se baseia nas fontes orais, as fontes escritas interagem, dialogam. Eu gosto também de destacar a distância cultural desse nível linguístico, entre a linguagem burocrática das instituições e a linguagem viva da gente comum, e às vezes uso os dois para mostrar o conflito cultural implícito na linguagem.

\footnotetext{
${ }^{5}$ Portelli, Alessandro. The Text and The Voice. New York: Columbia University Press, 1994. Sem tradução para o português.

${ }^{6}$ Se trata de Portelli, Alessandro. La città dell'acciaio. Due secoli di storia operaia. Roma: Donzelli, 2017. Sem tradução para o português.
} 


\section{E: Como estudar a história local?}

A. P: Sim, é uma historia local total. Interessa-me toda a cultura e toda a memória do lugar. Então, no livro existem capítulos sobre os artistas, sobre histórias de amor, sobre tudo porque assim se faz a história local, ela tem que ser completa e também porque se trabalha com a memória e a memória é uma relação entre o presente e o passado. A história deve chegar até o presente, esse é um problema porque enquanto você escreve, o mundo muda. Em Terni assim como em Halan [County], eu cheguei pensando que ia escrever a épica da classe operária e acabei escrevendo sobre a heresia da classe operária porque no tempo em que eles trabalhavam, eu escrevia, e as coisas iam mudando; e a luta de classe em Halan era uma luta de classe sindical, operária, e depois se tornou uma luta de classe implícita no meio-ambiente e agora o problema principal de Halan [County] é a medicina, esses analgésicos que se tornam drogas potente. Então, comecei a escrever a história oral de Halan [County], ainda nos anos de 1970, porém eu comecei o trabalho a sério em meado dos anos de 1980.

\section{E: Como entra a parte mais política ou econômica nessa história total?}

A. P: Teoricamente, a tentativa é de fazer tudo, de fazer uma história política, fazer uma história econômica, fazer uma história social e uma história cultural. Eu diria que a cultura é a primeira coisa, contudo, você tem que saber o que acontece na política e o que acontece na economia para entender como isso impacta na vida das pessoas - e como isso impactou - porque foi o que aconteceu com os indivíduos durante a guerra. Existem coisas das quais me havia inteirado quando escrevi meu primeiro libro sobre Terni, coisas que me pareciam que não eram locais. Então, isso me interessava, relatos de guerra, todos os relatos das mulheres sobre a saúde, os hospitais, e, um ano depois, me dei conta de que essa é a mesma história: sair de casa, tratar com o estado, com as instituições, com a tecnologia, com a morte. Para os homens é o serviço militar, para as mulheres é o trabalho de curar seus esposos, lidar com filhos quando estudam na escola, e essa razões que não estão nos livros porque não me havia dado conta de que a História local impacta na história geral. E por causa deste libro sobre Terni, agora que os publiquei juntos, que é uma história de dois 
séculos, me dei conta de que é uma história da Itália concentrada em um lugar, a independência, a questão das terras, a industrialização e a crise da industrialização. A história local é um concentrado e em Halan, eu dizia que a história dos Estados Unidos é muito acentuada lá porque aconteceu tudo ali. Existe uma relação metonímica entre a história local e geral.

E: O senhor entrevistou quantas pessoas mais ou menos? Dialogou informalmente com muita gente?

A. P: Falarei dos três principais projetos. Em Halan, realizei 160 entrevistas, 200 em Terni e 165 no projeto sobre o massacre nazista. Em outro projeto sobre um bairro periférico de Roma foram entrevistadas 80 pessoas. Eu sempre pensei que não se faz história oral com dez entrevistas. Bem, eu paro quando dizem que não tem mais energia e quando todas as entrevistas novas não trazem nada do que já não sabia. Mesmo que você nunca sabe se não existe um narrador extraordinário que poderia lhe dizer as mesmas coisas de uma maneira totalmente diferente, então você para sempre provisionalmente porque a história, a história... é continua.

E: O senhor afirma que não se faz História oral com dez entrevistas. Poderia falar um pouco mais o porquê? Quais indicações disso o senhor tem?

A. P: Bem, é um interpretação equivocada. Pode-se fazer o que você está dizendo, contudo, em meu caso como a tentativa é pesquisar toda a cultura... Nesse sentido, não dá pra entrevistar 05 operários numa fábrica que tem 130 anos de vida. E as mulheres? E os patrões? E os fascistas? $\mathrm{E}$ as crianças que nunca trabalharam numa fábrica? $\mathrm{E}$ os estudantes? E os padres? Você tem que entrevistar todos. Digo isso porque, para as entrevistas, o tempo passa e aparecem novos sujeitos, imigrantes. As últimas entrevistas em Terni foram com gente que chegou da Índia, da Romênia, do Marrocos. Não gosto de ser normativo. Quando fiz a investigação sobre o dia do massacre nazista, primeiro me perguntei sobre as pessoas e quem eram os partisanos. O bisavô do partisano que lançou a 
bomba que provocou a reação alemã foi enforcado em 1831 por haver liderado uma revolta contra os comuns em Palermo. O seu avô materno havia tentado deflagrar uma revolta em Palermo em 1856, coincidindo com a tentativa revolucionária de Carlo Pisacane, um dos heróis do movimento italiano em curso. O grupo clandestino partisano que ele liderava se chamava Grupo Ação Patriótica Carlo Pisacane. Então, naquele dia há toda uma história própria. De onde viam? Por que esse massacre em Roma é distinto da maioria dos outros massacres? Porque foi o única que teve lugar em uma metrópole da Europa Ocidental, as pessoas que os alemãs mataram vinham de todo a Itália. Existem história familiares que convergem. Contudo, minha motivação para fazer a pesquisa eram os sobreviventes. Entrevistei mulheres, esposas, filhos, filhas, algumas mães, pais e depois entrevistei a todos os partisanos porque o problema político desse massacre é a memoria. A história, os historiadores sabem muito bem o que aconteceu. Porém, no senso comum a culpa é dos partisanos. Dizem que os nazistas colocaram cartazes em Roma dizendo 'queremos que os partisanos se entreguem, caso contraio mataremos os reféns' Como os partisanos não se entregaram, então a culpa é deles. Não aconteceu simplesmente assim, não aconteceu com certeza, porem, esse o político importante é a memoria, porque a memoria é uma memoria que coloca em dúvida a moralidade da resistência, então é preciso entrevistar todo mundo.

E: Como nós podemos melhorar nossa relação com as pessoas que entrevistamos? O senhor disse na sua conferencia que o importante é estar muito aberto, deixar que a entrevista alimente novas perguntas e outros temas, dignos de interesse, que possam ser investigados.

A. P: A primeira coisa é que a palavra entrevista quer dizer que existem dois sujeitos que se olham reciprocamente, sendo assim não existe o observador e o observado. É preciso que a pessoa com quem você fala saiba um pouco sobre quem você é. Quando eu entrevistava as pessoas nos Estados Unidos que haviam se formado ou crescido em Company Towns, eu lhe dizia a eles que eu também cresci em um bairro de trabalhadores. Uma metáfora que eu utilizo para as entrevistas é que ela é parecida a uma dança, eu não sei dançar, contudo é como dançar. Você faz um passo com o seu partner e depois faz outro, é algo interativo. É um diálogo. Também é preciso respeitar os silêncios. A entrevista não é uma sessão de perguntas e respostas. É abrir um espaço: estou aqui para escutar o que você quer dizer. Eu 
também tenho umas coisas que talvez ele queira saber, porém, talvez, o tema principal seja o tema da entrevista. Entrevisto um minero porque quero saber como vivem e trabalham nas minas. Se entrevisto alguém a quem mataram o pai, quero dizer algo desse massacre nazista. Quando soube que os operários de Terni falavam dos fatos de 1949 e diziam que ocorreram em 1953, tive a ideia de escrever um libro sobre Terni entre 1949 e 1953. Fiz minha primeira entrevista com um operário que tinha se aposentado em 1953 e ele me disse que seu bisavô combateu com Garibaldi. No dia de seu casamento, largou a esposa e se foi com Garibaldi. Bem, o que fazer? Dizer, não, o que me interessa é esclarecer os eventos de 1949 e de 1953 ? O libro que acabo de publicar é um libro sobre Terni entre 1831 e 2014. Li muita literatura sobre História oral, mas tudo que sei, tudo que aprendi foi empiricamente. Por exemplo, você entrevista um analfabeto e você é professor, porém se o entrevista é porque o analfabeto sabe coisas que você não sabe, então essa é uma rica experiência, é uma aprendizagem. Meus estudantes me perguntam sobre as técnicas de entrevista e eu lhe digo: ter uma boa educação.

E: O senhor pergunta um pouco sobre a história de vida das pessoas quando inicia uma entrevista, como nós fizemos hoje?

A. P: Eu havia iniciado o projeto sobre os desaparecidos argentinos e ao fazer perguntas a um dos entrevistados - eu sabia que mataram seu pai - ele me contou coisas sobre sua família, sobre seus estudos; quando a entrevista toma outra direção, você vai com ela. A entrevista é aberta. Ninguém escuta essas pessoas. Estava entrevistando uma mulher em Terni porque ela era irmã de um comunista clandestino e a entrevista era sobre seu irmão, porém ela insistiu em contar-me sua história de amor com um fascista, assunto que eu havia descartado. Contudo, essa é uma história muito mais importante que a história do irmão. História de comunistas clandestinos aparecem em muitos lugares, porém histórias de amor como essa são únicas. Então, no libro existem duas linhas sobre seu irmão e um capítulo sobre ela. Chamamos de serendipity quando se encontra coisas que não estava buscando. 
E: Professor, o senhor que realizou muitos trabalhos, tem muitas experiências com a História oral, em algum momento houve alguma entrevista que não ocorreu como desejado? O que aprendeu todos estes anos?

A. P: Quando eu comecei a fazer a pesquisa em Halan County, estava me ajudando um jovem sociólogo afro-americano, filho de mineiros. Ele me levou para entrevistar a sua avó de 95 anos e ela passou duas horas e não me disse nada, absolutamente nada. Aprendi que para ela não era prudente falar com um branco; aprendi também que existem coisas que não se podem contar, não se podem dizer. Uma das coisas que acontecem sempre, entrevistando gente afro-americana são os silêncios. O ensinamento é esse. Outra vez a relação entre o passado e o presente. A relação neste caso era ainda mais traumática. Não de um trauma específico, de um elemento, de um acontecimento. O silêncio diz muito.

E: Como o senhor lida com a subjetividade das pessoas e com a possibilidade desta história em comum? Quer dizer, não estou falando de memoria coletiva e sim de subjetividade, esses testemunhos de pessoas individuais, de história em comum.

A. P: Olha, minha esposa é estatística. Para fazer estatísticas é preciso fazer um quadro, para fazer História oral é preciso um mosaico. O mosaico é uma imagem que está formada por partes totalmente diferentes. O trabalho do mosaicista é juntar e criar algo. Isso é um coisa. Outra metáfora é da linguagem. Essa ideia de Saussure de que todos recordamos como atos individuais da memoria e falamos com atos individuais da palavra... quando falamos o fazemos segundo uma gramática que é socialmente compartilhada e recordamos individualmente através de uma gramática socialmente compartilhada, porém essa se transforma em atos individuais da memoria. Por exemplo, a história das mulheres não existia e as mulheres começaram falando disso e agora a memoria social, na gramática da memoria social, não podemos deixar de falar de gênero.

E: Podemos falar sobre a ideia de sentido compartilhado das experiências individuais?

A. P: Sim, se você entrevista dez operários que trabalharam toda a vida no mesmo departamento da mesma fábrica, suas memorias são comuns e também porque talvez 
tenham falado disso, então isso seria a memoria compartilhada porque as experiências e os tempos são compartilhados. Não tenho nada contra se alguém falar que isso é memoria coletiva. Eu sei muito bem que isso não quer dizer que haja uma memoria no ar que paira sobre os indivíduos. O estruturalismo linguístico influenciou muito o pensamento dos grupos [de história] das mulheres, o pensamento da diferença.

E: Não pretendemos ser objetivistas, nem subjetivistas, nem queremos ser deterministas, porém não queremos fazer dos indivíduos apenas o que fazem os romancistas. Como lidar com isso?

A. P: Eu ainda me considero um marxista. Mas alguns têm me dito que escrevi cinco mil páginas e não há nenhuma citação de Marx. Desde quando era mais jovem, você pode associar alguma que escrevi com Marx, mas também coisas de Saussure, David Triesman, os sociólogos liberais americanos dos anos de 1950. Eles era como se fossem uma caixa de ferramentas dentro da qual eu pegava o que me servia para alguma tarefa específica. Metodologicamente, eu penso que isso seja válido, teoricamente eu já não sei... A subjetiva é um fato objetivo, ela existe, não é arbitrária. A subjetividade é como uma relação que uma pessoa tem com um acontecimento, com um contexto, com o passado. É a busca dessa entidade é o que faz as pessoas serem diferentes, cada pessoa é um sujeito diferente e tem uma relação distinta com o passado, com suas ideias.

E: Professor, a História oral, assim com as relações políticas, mudam com o passar do tempo. O senhor entende que tenha ocorrido alguma mudança entre a maneira como se trabalhava com a História oral a partir do início de sua carreira até agora? Houve alguma mudança significativa desde a sua geração?

A. P: No caso de Terni, as gerações dos anos de 1950, 60 e 70, possuíam diferenças políticas, não estritamente política, e sim no que diz respeito a uma ideia de futuro. $\mathrm{Na}$ grande revolta de 1953, a canção que os operário cantavam era "La gran victoria nos ha librado". Em 2004, os atos concretos, o material, era fundamentalmente o mesmo. Porém 
não havia nenhuma diferença política nem nenhuma perspectiva de diferença futura. Uma das coisas que parece que aconteceram é que a ideia de futuro se perdeu, foi esquecida. Isso porque a ideia de mudança social, de transformação da sociedade, e assim o futuro seria apenas o a tomada e controle do poder. A outra coisa é que as gerações mais jovens são muito mais organizadas. Isto não quer dizer que se expressem melhor, mas sim que elas são mais conscientes da grande gramática do discurso público. Quando eu comecei recuperar canções populares a gente cantava porque cantava. Agora todos se deram conta que há uma indústria da música popular. Por isso, a admiração pelas pessoas que eu entrevista. Hoje não há esse elemento, essa referencia comum de como seria a fábrica, o partido, o bairro. Por outro lado, em 1990, fiz um projeto sobre a memoria histórica de meus alunos, sobre o que eles sabiam a respeito dos anos de 1960, 1970 e 1980 e o porquê daquela luta. Bem, a história de vida de um jovem de 22 anos de hoje é muito mais complexa que a história de vida de um operário dos anos de 1950, 1960. Um operário que entrou na fábrica aos 14 e saia aos 70 anos passava por toda uma história épica de greves. Mas meus alunos haviam participado do projeto Erasmus, haviam viajado meio mundo, haviam trabalhado como voluntários em Kosovo. Haviam estado na escola e participado na história traumática dos fatos que ocorreram no ano de 2001, da matança policial de 2000, por isso suas histórias de vida eram mais enredadas que as histórias dos operários; assim nem tudo é todo negativo. O que falta de verdade é uma ideia de mudança no timbre da geração de 2001. Eles diziam que outro mundo é possível, agora parece que não, que a ideia de futuro se perdeu; mas, talvez, estejam perto do rumo certo... por outro meio.

E: O senhor percebe alguma distinção ou semelhança entre a História oral feita na Europa e a História oral feita na América, no Brasil, por exemplo. Existe algo, em seu ponto de vista, que é próprio ou característicos de vocês?

A. P: São histórias muito diferentes. Nos Estados Unidos, conhecem apenas o que se publica nos Estados Unidos. Na Europa, os franceses conhecem apenas o que é publicado na França. No Brasil, os historiadores orais conhecem tudo, os franceses, os mexicanos e italianos... Em toda América Latina, México, Brasil, menos na Argentina, existem ainda culturas orais nativas que influenciam a história oral de uma metrópole como São Paulo. 
Então, esse diálogo entre a modernidade e culturas orais nativas parece-me uma coisa muito interessante na América Latina. Não é causalidade que Brasil e México sejam metrópoles, centros internacionais muito mais interessantes que Estados Unidos...

E: Qual é a razão da disputa entre alguns oralistas anglo-saxões e os mediterrânicos e latino-americanos?

A. P: Existem muitos estereótipos e os estereótipos atuam na vida real. É como a memoria, a memoria equivocada sobre as forças clandestinas se tornam uma força política quando alimentam a ideologia do antifascismo. Nas primeiras vezes que eu vim ao Brasil, a impressão que tive é que os intelectuais daqui se sentiam marginalizados, subalternos. Europa era o centro. Então, eles eram os únicos que liam tudo que se fazia na Europa.

E: Uma coisa sobre a qual gostaríamos de conhecer a sua opinião é o caso desses pesquisadores que tem um gravador e realizam algums perguntas em apenas 10 minutos ou um pouco mais de tempo a algums pessoas e afirma que estão fazendo História oral. Isso é História oral?

A. P: Essa é uma coisa que digo todos os dias: não se faz História oral com dez entrevistas. Gianni Bosio, de quem falei antes, não falava de História oral, falava sobre o uso de fontes orais. O que são fontes orais? Uma entrevista, uma citação. Fazer História Oral é algo diferente disso, é colocar a realidade no centro. A realidade é o ponto de partida em tudo isso e procurar o que diz específicamente o que a fonte oral pode ser. Isso é simplesmente utilizar uma entrevista para alcançar um objetivo. Perfeitamente legítimo. Mas eu utilizo as fontes orais dentro de um todo. História oral é colocar a oralidade no centro. A primeira informação, o primeiro que você sabe sobre um acontecimento, você sabe a partir da oralidade, de uma entrevista. Depois você pode verificar nos arquivos, porém o ponto de vista é o da oralidade. 
E: Quando afirmamos que preferimos trabalhar com fontes orais e declaramos que fazemos trabalho interdisciplinar alguns antropólogos e sociólogos não parecem muito felices com nossos comentários.

A. P: A História oral é diferente da antropologia porque o enfoque é o passado. É a relação com o passado. O enfoque é o tempo. São coisas distintas. Eu sempre ouvi dizer que são quatros coisas diferentes: nós historiadores queremos conhecer o que aconteceu, os antropólogos procuram os frutos culturais; e historiadores orais colocamos nossa humanidade na redação, utilizando a imaginação. Somos um pouco artistas porque utilizamos as técnicas da análise literária, linguística. Escrever uma Historia oral é também um tarefa literária e artística porque você tem que dar conta da qualidade do discurso, não apenas o dos entrevistados, mas também todo o trabalho de procurar palavras, dar performance, construir o diálogo. Meus modelos de escrita são de auto espaços, quando uma pessoa escreve histórias que se encontram com outras história através dos modelos de escrita. Estamos no cruzamento de todas as ciências humanas. Estamos no centro mesmo que a História oral pareça ser uma coisa marginal no que diz respeito à história que é ensinada.

E: O senhor disse em sua conferencia, não sei se anotamos corretamente, que Umberto eco afirmava que nós não podemos escolher o que queremos recordar.

A. P: Umberto Eco falava que existem coisas que esquecemos porque não significam nada e outras coisas que significam demais. O esquecimento está em muitas formas de memoria.

E: O senhor disse também que esquecer não é apenas uma eleição cultural, mas é também descartar aquilo que não serve, que não tem utilidade.

A. P: A memoria é uma busca de sentido em relação ao passado, é o que carece de sentido em relação a este ou àquele evento. Por exemplo, eu não me recordo do que comi no dia me 
meu aniversario de 1962, porém recordo muito bem o que comi no meu aniversario em 1952 já que a minha mãe me perguntou o queria comer e eu respondi que queria espaguete ao burro, que é algo bem simples. Esse dia tem a ver com a minha relação com minha mãe, tem um sentido. E assim me lembro muito bem porque tem sentido. Aconteceu assim através da busca de quem sou eu e qual relação possuo com a minha vida, com meu passado.

E: Qual foi a sua militância política?

A. P: Eu sempre coloquei-me na extrema direita da extrema esquerda. Estava em Il Manifesto. Eu nunca fui do Partido Comunista porém comecei a fazer militância com Il Manifesto. Como a pergunta é por minha vida de militante, sou um comunista sem partido.

E: Será que ainda continuamos "procurando a verdade"? Será que você com sua história total não busca esse fato, essa verdade, buscando entender na sociedade, um grupo humanos?

A. P: Existem um personagem de um romance de Hogner, que é um personagem muito negativo, horrível, porém ele diz uma coisa fantástica depois da guerra civil: "nos mataram mas ainda não nos derrotaram." Mataram-nos: os movimentos, a classe trabalhadora. Quando desalojaram famílias de Barcelona, onde meu filho estava trabalhando como antropólogo e onde conheceu sua namorada, o slogan dizia, quando derrubaram as casas, "estamos vivendo!"

E: Como o senhor entende a função ou a contribuição da História oral no enfrentamento dos desafios de nosso tempo?

A. Uma coisa que estamos fazendo em Roma, como um exemplo de nossa essência cultural, é criar corais entre amigos, difundir e ajudar a música migrante. Uma das coisas que facilitam o crescimento atual de movimentos de extrema direita na Itália não é tanto o 
fato de que não tenham memoria, mas tenham memorias parciais, então é necessário um trabalho sobre sua história e sobre sua memoria. É um trabalho de aprofundar uma alternativa porque uma das coisas que acontece na Itália é que existem milhares de italianos em São Paulo e nós, os italianos, somos contra os imigrantes. Uma estatística fala que existem 5.300,00 estrangeiros na Itália e existem 5.800,00 italianos. A Itália segue sendo um país de imigração. Este fato de que fomos migrantes, fomos discriminados é um fato que se ignora completamente. Se fala, bem, vamos tratar os imigrantes como os outros sempre nos trataram. É uma memoria que não produz solidariedade. Então, trabalhar sobre memorias e solidariedade é muito importante. A música é uma das poucas coisas ao redor da qual as pessoas se juntam. Existem dezenas de corais em Roma. Milhares de pessoas que se juntam para cantar e em quase todos eles existe algo de político. Minha mulher que canta em um coral de música, acaba de escrever um livro político também. Em uma sociedade que atomiza, a música é uma das poucas coisas em que as pessoas se juntam e encontram suas voz, então sempre pensei que a música, não a dos grandes artistas como Giovanna Marini na Itália, mas a música como um fato social de base, os músicos de estrada, a gente que canta, tem aí uma das poucas coisas que fazem em sociedade. Cantar se tornou um ato de existência. 